\title{
O conceito freudiano de regressão e a prática da psicoterapia em ambulatório de hospital universitário
}

\author{
Ana Cleide G uedes Moreira
}

Este trabalho, examinando o conceito freudiano de regressão $e$, buscando identificar e analisar sua presença na prática da psicoterapia de orientação psicanalítica, em ambulatório público hospitalar, objetiva contribuir para a teoria da técnica psicoterápica.

Palavras-chave: Psicanálise, transferência, psicopatologia fundamental, regressão 
O conceito de regressão postulado por Freud vai desempenhar um papel de importância crescente em seu trabalho, sendo definido, inicialmente, como a direção dos processos psíquicos, desde a extremidade motora até a extremidade perceptiva do aparelho psíquico, permitindo a transformação de pensamentos em imagens, durante a formação do sonho. Esta definição apresentada em $A$ interpretação dos sonhos (1900) permanece válida ao longo de sua obra e, faz ainda uma última aparição no "Esboço de psicanálise” (1938).

A psicanálise dispõe de um corpo teórico que permite sustentar que a regressão é parte dos processos psíquicos como o sonho e a frase de espírito, que se apresenta como sintoma, e que é necessário levá-la em conta e definir tecnicamente meios de lidar com os fenômenos regressivos na prática clínica (Etchegoyen, 1987). Neste trabalho, considera-se que examinar a problemática da regressão em um dispositivo clínico psicoterápico exige a investigação do conceito enquanto metapsicologia (Fédida, 1996) para, a seguir, visitando os problemas colocados pela clínica, relacionar a análise dos modos de subjetivação psicopatológicos identificados e a definição da direção do tratamento.

Estes objetivos reclamam uma ampliação da perspectiva, e é no campo da Psicopatologia Fundamental que vamos encontrar lugar para esta pesquisa. Primeiro, porque nele se busca sustentar uma posição para além das diferenças escolásticas permitindo a visitação da fronteira com outros campos de saber sobre o pathos, uma vez que a prática clínica de que aqui se trata se dá em um contexto específico, localizando a investigação em uma instituição médicohospitalar que, como tal, não está em regime de análise, sem que, com isso, fique elidida sua especificidade. Em segundo lugar, porque são nos fundamentos de uma história de vida, 
relatados por seu protagonista em sua singularidade, que se pode encontrar aquilo que nos aproxima de elementos universais da constituição da subjetividade e da produção do sofrimento psíquico, visando uma teorização que permita emergir da investigação clínica o caminho de acesso simbólico para processos psíquicos inconscientes, constitutivos da dimensão humana.

Passemos agora a examinar a concepção freudiana, a partir das formulações contidas em A interpretação dos sonhos, no notável capítulo VII, em que Freud (1900) se dedica a apresentar sua concepção de aparelho psíquico, no qual a noção de regressão é fundamental, dedicando-lhe toda uma seção. Transcrevemos abaixo o trecho em que ele propõe a distinção entre três tipos de regressão, em nota acrescentada em 1914:

Assim, cabe distinguir três tipos de regressão: a) regressão tópica, no sentido do quadro esquemático dos sistemas $\Psi$ que explicamos atrás; b) regressão temporal, na medida em que se trata de um retorno a estruturas psíquicas mais antigas; e c) regressão formal, onde os métodos primitivos de expressão e representação tomam o lugar dos métodos habituais. No fundo, porém, todos esses três tipos de regressão constituem um só e, em geral, ocorrem juntos, pois o que é mais antigo no tempo é mais primitivo na forma e, na tópica psíquica, fica mais perto da extremidade perceptiva. (p. 501)

Segundo Etchegoyen (1987), a classificação de Freud continua vigente, mas no pensamento freudiano os conceitos de regressão e fixação, ainda que sejam a chave explicativa da psicoterapia, nunca foram transportados à situação analítica (p. 324). Ou seja, a reflexão sobre a teoria da técnica psicanalítica é produto dos autores que o sucederam e há diferenças entre as escolas psicanalíticas no modo de conceber e lidar com a regressão ao longo do processo analítico. Em um capítulo dedicado a estudar como se relacionam o enquadre e a regressão no processo analítico, considera que é um problema de alta densidade teórica ao qual nem todos os investigadores dão igual importância, embora na prática de todos os dias se torne simples e sem maiores complicações, aparecendo como inerente ao processo psicanalítico (ibid.). Após dedicar um extenso estudo ao tema, Etchegoyen oferece uma síntese que transcrevemos abaixo:

Vimos, então, a relação do processo psicanalítico com os fenômenos da regressão e progressão inerentes à própria definição de processo, que pode ser explicada com dois enfoques teóricos, o que sustenta que a regressão depende do enquadre e o que, ao contrário, afirma que a regressão deriva da enfermidade. A primeira teoria entende a regressão como um produto artificial do setting, graças ao qual o tratamento analítico pode ser efetuado e, por isso, qualificado como regressão terapêutica. A teoria oposta admite uma regressão psicopatológica, à qual o enquadre analítico se acomoda da forma mais racional possível. (p. 342) 


\section{$\begin{array}{lllllll}R & E & V & \text { I } & S & T & A\end{array}$ \\ LATIN O AMERICANA \\ DE PSICOPATO LOGIA \\ F U N D A M E N T A L \\ ano $X$, n. 1, mar/2007}

Em suas considerações, Etchegoyen vai propor que existe ainda uma terceira possibilidade, atribuída a Winnicott, na qual a cura consiste em que se possa desenvolver um processo de regressão a partir do qual a natural tendência do indivíduo a crescer sadiamente possa restabelecer-se (ibid.).

A explicitação da posição de Freud quanto à técnica a ser utilizada na presença da regressão no tratamento analítico, ainda segundo Etchegoyen, está contida entre as breves referências à regressão nos artigos sobre a técnica. Merece destaque esta, contida no artigo “A dinâmica da transferência”, de 1912, em que Freud afirma que a transferência aparece na psicanálise como uma resistência, quando a libido, inteiramente ou em parte, entrou em curso regressivo e reviveu as imagos infantis do indivíduo, e o tratamento analítico então passa a segui-la, buscando torná-la acessível à consciência (p. 137). Ou seja, para Freud, do ponto de vista técnico, há regressão quando há transferência e, como se trata de uma resistência ao processo analítico, qualificada como a resistência mais poderosa ao tratamento, ela deve tornar-se consciente. Então, a transferência no processo analítico pode ser considerada uma regressão temporal, no sentido cronológico, pois o paciente investe o analista com suas imagos infantis. Em “Esboço de psicanálise” Freud (1940[1938]) afirma:

A transferência é ambivalente: ela abrange atitudes positivas (de afeição), bem como atitudes negativas (hostis) para com o analista, que, via de regra, é colocado no lugar de um ou outro dos pais do paciente, de seu pai ou de sua mãe. (p. 202)

Como se vê, é no campo da transferência que se coloca para Freud a questão técnica decisiva da regressão em uma análise. De fato, a regressão transferencial tem sido considerada um dos critérios diferenciais entre psicoterapia e psicanálise em práticas clínicas (Kernberg, 2003; Mezan, 1998 e Costa, 1998), embora haja autores que a considerem resquícios da concepção evolucionista presente em Freud que deve ser abolida (Figueiredo, 2004). Veja-se a seguir as relações entre psicanálise e psicoterapia em autores que destacam a regressão como um critério diferencial entre elas.

Segundo Mezan é preciso situar o contexto histórico em que se deram as origens de psicoterapia, entre o final do século XIX e início do século XX. Como se sabe, Freud publica, em 1904, o artigo “O método psicanalítico de Freud”, em 1905 o artigo “Sobre a psicoterapia” e, nesses trabalhos, irá afirmar que a psicanálise é uma psicoterapia, porém, e aí entra o argumento fundamental, ele podia dizer que a psicanálise era uma forma de psicoterapia porque era, de fato, a única psicoterapia, já que outra modalidade de tratamento para curar as doenças ditas "nervosas” por meios psíquicos e não físicos, a saber, a hipnose, obtendo seus resultados por sugestão, não é considerada terapêutica (Mezan, 1998, p. 314). 
Mezan irá discorrer sobre a inserção da psicanálise, inicialmente no campo da medicina, passando a mostrar como a noção médica de cura veio a se tornar muito problemática na psicanálise, uma vez que o objetivo desta não é eliminar os sintomas, e sim modificar em profundidade toda a estrutura psíquica cujo funcionamento origina e mantém aqueles sintomas. Ora, a partir da psicanálise, vieram a se diferenciar outras psicoterapias, o que começou a ocorrer com as dissidências dentro do próprio movimento analítico (Freud, 1914), como as de Jung, Adler, Reich entre outros. Essas dissidências, ao recusar partes das concepções freudianas, foram também sendo levadas a alterar ou suprimir as partes do método clínico que se fundamentavam naquilo que estavam rejeitando. E Mezan dá um exemplo que bem ilustra seu argumento: quando Jung rejeita a teoria de sexualidade infantil deixará de investigar as manifestações adultas da sexualidade, entre as quais se conta a transferência no sentido psicanalítico e logicamente deixará de interpretar a transferência da maneira como o fazia Freud. $\mathrm{O}$ que esse autor vai considerar uma das diferenças fundamentais entre a psicanálise e as terapias não-psicanalíticas consiste no fato de empregar-se ou não a metapsicologia freudiana, ou de origem freudiana, para compreender o processo terapêutico, o que nos leva diretamente à questão que aqui mais interessa: um elemento diferenciador entre a psicanálise strictu sensu e as diversas psicoterapias consiste no emprego metódico da regressão. No seu entendimento, a regressão é um processo psíquico que é muito facilitado pelas condições do setting clássico, isto é, o divã, o atendimento individual várias vezes por semana e a neutralidade de princípio da análise. Seu argumento é que algumas terapias estão interessadas na regressão, outras não; a psicanálise está entre as primeiras, porém a diferença está no manejo deste processo, que para o analista está estreitamente conjugado com a transferência e requer um tipo peculiar de interpretação (Mezan, 1998, p. 317). Assim sintetiza sua perspectiva:

São questões complexas, naturalmente, e que aqui só posso mencionar de passagem: mas do meu ponto de vista, prefiro chamar de psicanálise somente os métodos que trabalhem com estas - todas e cada uma - características: dispositivo que favoreça a regressão (o desamarrar dos nós da vigilância consciente, como propicia a associação livre), interpretação da resistência e da transferência, vinculação destas com a sexualidade infantil, e hipótese fundadora de que os conflitos são inconscientes porque estão submetidos à pressão das defesas do ego. Pode haver muitos e bons métodos que trabalhem com pressupostos diferentes, mas eu não os chamaria de psicanálise, e para eles reservo a designação geral de "psicoterapias". (p. 318)

Passemos agora ao exame do artigo de Gley Costa, inteiramente dedicado a estabelecer as diferenças e respectivas especificidades entre a psicanálise e a psicoterapia de orientação analítica, na qual se encontra a importante afirmação 


\section{$\begin{array}{lllllll}R & E & V & \text { I } & S & T & A\end{array}$ \\ LATINOAMERICANA \\ DE PSICO PATO LOGIA \\ F U N D A M E N T A L \\ ano $X$, n. 1, mar/2007}

de que são diferentes os níveis de regressão proporcionados. Segundo Costa (1998), a psicanálise oferece melhores condições de regressão que possibilitam a expressão das pulsões pré-genitais por meio de defesas primitivas, o que permite a elaboração de núcleos psicóticos do sujeito. Já na psicoterapia, a regressão é menos intensa e se encontra limitada pelo constante contato com a realidade contingente, resultando que os mecanismos de defesa serão mais evoluídos e relacionados com as pulsões da vida genital infantil no contexto do complexo de Édipo (p. 885). Segundo ele:

Uma diferença marcante entre a psicanálise e a psicoterapia, inspirada nos conhecimentos psicanalíticos, observa-se na técnica de interpretação. No tratamento analítico, a interpretação é fundamentalmente transferencial, considerada mutativa. Mediante esta interpretação efetua-se uma revivência da experiência infantil no aqui e agora da sessão, ajuizada pela ótica de um ego adulto. Em contrapartida, a psicoterapia enfoca preferentemente os processos psicodinâmicos e transferenciais ocorridos com terceiros, evitando a interpretação transferencial que exige um manejo adequado do setting, característico do processo analítico. Por esta razão, a experiência psicoterapêutica tende a resultar mais teórica e intelectualizada. Os traços de dependência relacionados com o caráter, que surgem na transferência, idealizando o analista, não costumam ser resolvidos neste processo, que se encontra limitado quanto à obtenção do insight e à mudança psíquica. (p. 894)

Mais uma vez, é a regressão que jogará o papel decisivo possibilitando o acesso aos objetos internos cuja origem infantil exige um retorno das lembranças mais precoces. Como é sabido, Freud (1917) afirmou que a regressão pode levar o neurótico a retroceder tanto que pode atingir a época em que era um bebê de colo, seja que dessa época se lembre ou que a imagine a partir de indícios posteriores (p. 427). Para os dois autores apresentados, a regressão é mais intensa e seu manejo é mais facilitado na condição da psicanálise clássica do que na psicoterapia, uma posição que encontra em Fédida uma análise instigante, que permite ampliar o campo de debate abrangendo as posições divergentes.

Fédida (1996) considera a regressão um verdadeiro conceito metapsicológico, que analisa em um texto inteiramente dedicado a ele, no qual vai desenvolver sua concepção da função restauradora de regressão, possibilitada pelo que chama de imaginação analógica e metafórica do analista, graças a qual o paciente pode extrair recursos terapêuticos de sua regressão no tratamento. Fédida vai afirmar que o que limita o uso que fazemos habitualmente do conceito de regressão é o nosso “psicomorfismo”, ou seja, uma tendência que privaria o analista da fantasia das formas, das deformações e das transformações que, todavia, lhe são sugeridas palas expressões teratológicas dos sintomas. Para ele não importa quão frágil seja, 
a lembrança é este pensamento de imagem que conserva os traços de uma forma desaparecida podendo, então, desenhá-la sob uma nova forma (p. 215).

Nesse sentido, para esse autor, retomar as formulações freudianas e ferenczianas, permite afirmar que a regressão dá acesso, pela análise, ao conhecimento dos inícios da humanidade, e abre caminho para uma reconstrução da infância da espécie, o que implica que, ainda sendo a dinâmica de um processo possibilitado pela construção da situação analítica, não se reduz à dimensão de uma regressão corporal, psicopatológica (p. 221).

Passemos agora a tratar mais detalhadamente de seu livro intitulado Dos benefícios da depressão: elogio da psicoterapia (2002) em que o tema da regressão ocupa um lugar central de sua análise. Tendo formulado a idéia de que a psicoterapia é uma análise complicada dedica-se a explicá-la. Em suas palavras:

Lembrando que a psicoterapia faz parte integrante da psicanálise, o que me interessa em primeiro lugar é a necessidade (que muitas vezes ressaltei) de conceber uma psicoterapia como uma análise complicada. A psicoterapia não poderia, a meu ver, ser concebida nem como uma simples implicação da dimensão terapêutica da psicanálise nem como uma das aplicações da psicanálise à prática dos cuidados. Vou tentar explicar aqui no que uma psicoterapia é uma análise complicada, a partir de orientações esclarecendo meu ponto de vista, onde o que está em jogo, de modo muito claro, é solicitar da parte dos psicanalistas - e das instituições psicanalíticas, nas responsabilidades que lhes cabem quanto à formação dos analistas - que eles considerem plenamente, seja técnica, seja teoricamente, essa complicação que já foi, no entanto, muito evidenciada pelo que se pode chamar de “clínica dos casos difíceis”. (p. 142-3, grifos do original)

Para Fédida, a psicoterapia com pacientes psicóticos, os pacientes-limites e as crianças, praticadas por psicanalistas, embora freqüentemente sejam maltoleradas pelas sociedades de psicanálise, possuem um grande valor na medida em que revelam uma riqueza técnica e metapsicológica que poderia beneficiar a concepção do tratamento analítico padrão. Segundo Fédida, a compreensão dos processos de regressão refinou-se em estreita relação com a psicoterapia de pacientes deprimidos - especialmente com M. Balint e D. W. Winnicott - pois se a depressão pode ser vista como estado de regressão, é a situação analítica que dá a este último as condições técnicas de tratamento, de atenção, assim como de reanimação da vida psíquica. A importância concedida ao enquadre (regularidade e duração das sessões, lugar protegido, silêncio) confirma essa conjuntura entre acolhida do estado deprimido e aceitação (ibid., p. 34). O que está em jogo no tratamento é o tempo da regressão, distinto do tempo do retraimento. Por tempo de regressão, o autor entende o tempo do retorno das experiências psíquicas e corporais anteriores, especialmente dos primeiros anos de vida, e o enquadre da psicoterapia serve para tornar possível a redescoberta dessas experiências. Já o 


\section{$\begin{array}{lllllll}R & E & V & I & S & T & A\end{array}$ \\ LATIN O AMERICANA \\ DE PSICO PATO LOGIA \\ F U N D A M E N T A L \\ ano $X$, n. 1, mar/2007}

tempo de retraimento pressupõe a descoberta de pensamentos e de fantasmas constitutivos da vida interior e que supostamente não devem ser comunicados, ao menos diretamente. Em suas palavras: "A modulação tonal dos afetos sentidos - restituída pela transferência na análise - passa por uma fala que dispõe de tempo para falar" (ibid., p. 31, grifado no original).

Passemos à questão da transferência, a partir da retomada de Fédida ao texto freudiano publicado pela primeira vez em 1890, intitulado "Tratamento psíquico" (Freud, 1905) que corresponde, segundo ele, a um condensado da teoria da ação psicoterápica e que já anuncia o que será entendido como teoria de transferência. Nesse texto, Freud apresenta a idéia de alucinação negativa, que é, para Fédida, uma dimensão maior da regressão transferencial (Fédida, 2002, p. 151). Citemos Freud:

Tal como o hipnotizado pode ser forçado a ver o que não está ali, pode também ser proibido de ver algo que está presente e que pretende impor-se a seus sentidos, como, por exemplo, determinada pessoa (a chamada "alucinação negativa”); essa pessoa descobre então ser impossível fazer-se notar pelo hipnotizado através de qualquer tipo de estimulação; é tratada por ele "como se fosse feita de vento [ou transparente como o ar, na tradução de Fédida]”. (p. 280)

A partir dessa passagem freudiana Fédida (2002) se pergunta se, de fato, no tratamento psicanalítico o enquadre proporciona as condições favoráveis para que a presença do analista em pessoa facilite essa alucinação negativa que o ausentiza; então, o próprio de uma psicoterapia não seria fazer coexistir as manifestações comunicacionais da presença e da ausência necessárias para a regressão? Para ele, esta é uma das dificuldades maiores da prática psicoterápica, uma vez que o analista deve se deixar modificar pelas transferências e, ao mesmo tempo, qualquer excesso de neutralidade e uma presença silenciosa demais podem suscitar no paciente um sentimento de aniquilamento que ele teme acima de tudo (p. 152).

Para Fédida na regressão transferencial é como se se tratasse, a cada vez, de retornar à origem da psicanálise, ou seja, ao que é solicitado do originário (primitivo ou arcaico) e que poderá assim levar a uma atividade de construção. Mas, aqui, retornar à origem da psicanálise, ao modo de Fédida, é de fato voltar a esse momento em que se abre o caminho para a obra psicanalítica de Freud, que é a $A$ interpretação dos sonhos, mais precisamente o sonho da injeção de Irma, que considera, seguindo Lacan, o sonho de angústia e da regressão do eu do analista: regressão do eu do analista em seu sonho, que parece ser o único recurso do analista para se apropriar de seu fracasso terapêutico e ver se desvelar a solução. Para Fédida (2002), evocar este sonho como o protótipo do sonho do analista é perguntar se não é desse sonho que precisamos no tratamento de cada um de nossos pacientes (p. 153). 
Passemos agora a um fragmento clínico, pois a clínica é a razão maior para um trabalho como este.

Ela começou a freqüentar meu consultório no ambulatório há mais de três anos. Aqui vamos chamá-la dona Maria. Veio indicada pela enfermeira da equipe multiprofissional do programa de diabetes, pois apresentava alto índice de glicemia embora tomasse, regular e diariamente, insulina. Tratava-se de uma senhora de idade avançada, pequenina, com olhos azuis que devem ter sido muito bonitos, como ela própria. Não sabia bem o que viera fazer ali, mas foi logo conversando e revelou que não fazia a dieta rigorosa, pois não queria abrir mão de certos alimentos de que gostava muito: o açaí e a farinha de mandioca, por exemplo. Mas sabia que o diabetes estava prejudicando sua visão. Inicialmente, eu a atendia a cada quinze dias, depois passou a vir semanalmente. Mostrava-se sempre cordata em relação ao enquadre estabelecido para sua psicoterapia: "eu não me mando, quem me manda é a senhora, doutora”. Não me escapava esse lugar idealizado em que me colocava e, ao longo de seu processo psicoterápico, estive observando, em silêncio, os sucessivos lugares que me atribuía. Às vezes me chamava de vizinha, e explicava, consertando-se e retornando ao “doutora”, que sua vizinha é uma amiga muito querida, fora casada com o irmão de seu marido, e com ela sustenta essa amizade há mais de cinqüenta anos.

Certa época chegou dizendo que meus cabelos eram iguais aos de sua mãe e passou a falar dela. Não deixei de me surpreender, a princípio, com sua aparente acuidade visual. Lembra de sua mãe até hoje, “como se viva estivesse”. Talvez estes tenham sido os momentos mais dolorosos, quando teve que fazer um trabalho de luto por seu neto, que morreu neste mesmo hospital que freqüentava para se tratar. Seu neto muito amado, a única pessoa, além de sua mãe, que ela se permitiu receber o gesto carinhoso de pentear os seus cabelos, que hoje usa curtinhos, mas que eram longos desde a infância até os seus 24 anos, quando ainda vivia sua mãe, com quem era muito “unida”, mesmo quando já tinha seu primeiro marido e alguns filhos. Hoje, quase não sai de casa, mas não perde uma só sessão de sua psicoterapia, afirma. Só duas coisas a levam a sair de casa rotineiramente: suas vindas ao hospital e a visita mensal ao túmulo do neto querido.

Eu me pergunto onde essa pequena senhora encontrou forças para fazer o trabalho de luto que veio fazendo em sua psicoterapia, enquanto outras dores foram atingindo-a, entre os vários filhos e netos que nestes tempos padeceram também, de Aids, de tuberculose, de uso abusivo de álcool, de desemprego, e de viver com dois ou três reais por dia, muitos ainda sob seu teto, à custa de sua miúda aposentadoria.

Aos poucos foi revelando que se sentia disposta a aderir ao rigor da dieta. Chegou a se programar para fazer caminhada diária até a casa de seu irmão - 


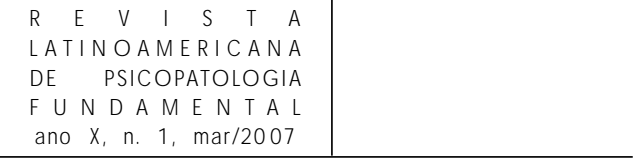

agora também perdido. E, finalmente, nos últimos exames realizados, comemorou a normalização de sua taxa de glicemia, algo que a deixou muito contente. Nada sabemos dessa melhora, nem se será duradoura. Ela segue tomando insulina e fazendo sua dieta, tomando seu açaí com farinha ou comendo um doce apenas uma vez ou outra. E semanalmente está ali na sala de espera, pacientemente esperando sua hora para então tomar seu lugar na poltrona e retomar a construção da história de sua vida.

Vimos no início deste trabalho que, para Etchegoyen a relação do processo analítico com os fenômenos de regressão e progressão inerentes à própria definição de processo poderia ser explicada por dois enfoques teóricos, sendo um que sustenta que a regressão é produto do enquadre e outro que a regressão deriva da enfermidade. Agora, para concluir este trabalho, temos que reconhecer que a concepção de Fédida implica que esses dois enfoques não se opõem necessariamente, estando ambos presentes na psicoterapia de pacientes deprimidos, e é em sua dimensão de regressão transferencial que ele se torna central na análise de um processo psicoterápico. Além disso, vimos que a regressão é considerada um elemento diferencial entre psicanálise e psicoterapia. Como espero ter demonstrado, na psicoterapia de dona Maria foram dispostas as condições para que um trabalho de luto possa ter contribuído para a elaboração das perdas afetivas, evitando modos de subjetivação psicopatológicos, como uma possível melancolia senil, com graves e dolorosas conseqüências. E o que deu a direção desta análise complicada foi o conceito de regressão em sua dimensão de transferência.

\section{Referências}

Costa, G. Psicanálise e psicoterapia: o vértice do psicanalista. Revista Brasileira de Psicanálise. Porto Alegre, v. 32, n. 4, p. 885-903, 1998.

Etchegoyen, R. Fundamentos da técnica psicanalítica. Porto Alegre: Artes Médicas, 1987.

FédidA, P. O sítio do estrangeiro - A situação psicanalítica. São Paulo: Escuta, 1996.

Dos benefícios da depressão: elogio da psicoterapia. São Paulo: Escuta, 2002.

Figueiredo, A. C. Vastas confusões e atendimentos imperfeitos: a clínica psicanalítica no ambulatório público. 4. ed. Rio de Janeiro: Relume-Dumará, 2004.

Freud, S. (1900). A interpretação de sonhos. In: Edição Standard Brasileira das Obras Psicológicas Completas de Sigmund Freud. 2. ed. Rio de Janeiro: Imago, 1988. v. V.

(1904[1903]). O método psicanalítico de Freud. In: Edição Standard Brasilei- 
ra das Obras Psicológicas Completas de Sigmund Freud. 2. ed. Rio de Janeiro: Imago, 1988. v. VII.

(1905[1904]). Sobre a psicoterapia. In: Edição Standard Brasileira das Obras Psicológicas Completas de Sigmund Freud. 2. ed. Rio de Janeiro: Imago, 1988. v. VII.

(1905[1890]). Tratamento psíquico (ou mental). In: Edição Standard Brasileira das Obras Psicológicas Completas de Sigmund Freud. 2. ed. Rio de Janeiro: Imago, 1988. v. VII.

(1912). A dinâmica da transferência. In: Edição Standard Brasileira das Obras Psicológicas Completas de Sigmund Freud. 2. ed. Rio de Janeiro: Imago, 1988. v. XII.

(1914). A história do movimento psicanalítico. In: Edição Standard Brasileira das Obras Psicológicas Completas de Sigmund Freud. 2. ed. Rio de Janeiro: Imago, 1988. v. XIV.

(1917[1916-1917]). Conferência XXIII. Os caminhos da formação dos sintomas. In: Edição Standard Brasileira das Obras Psicológicas Completas de Sigmund Freud. 2. ed. Rio de Janeiro: Imago, 1988. v. XVI.

(1940[1938]). Esboço de psicanálise. In: Edição Standard Brasileira das Obras Psicológicas Completas de Sigmund Freud. 2. ed. Rio de Janeiro: Imago, 1988. v. XXIII.

Kernberg, O. F. Psicanálise, psicoterapia psicanalítica e psicoterapia de apoio: controvérsias contemporâneas. In: GrEen, A. (org.). Psicanálise contemporânea. Revista Francesa de Psicanálise. Rio de Janeiro: Imago; São Paulo: SBPSP, Depto. de Publicações, número especial, p. 23-49, 2003.

Mezan, R. Tempo de muda: ensaios de psicanálise. São Paulo: Companhia das Letras, 1998.

\section{Resumos}

Este trabajo, examinando el concepto freudiano de regresión y, buscando identificar y analizar su presencia en la práctica de la psicoterapia de orientación Psicoanalítica, en ambulatorio público de hospital, objetiva contribuir para la teoría de la técnica psicoterápica.

Palabras claves: Psicoanálisis, transferencia, psicopatología fundamental, regresión

Ce travail a pour but d'identifier et d'analyser l'usage du concept freudien de régression dans la pratique de la psychothérapie de base psychanalytique dans les 
services d'urgences d'un hôpital publique. Ce faisant, le texte cherche à contribuer à la théorie de la technique psychothérapique.

Mots clés: Psychanalyse, transfert, psychopathologie fondamentale, régression

This article discusses Freud's concept of regression and seeks to identify and analyze the presence of regression in psychoanalytically based psychotherapy as used in treatment at an outpatient service of a public hospital. The objective is to contribute to the theory of psychotherapeutic techniques.

Key words: Psychoanalysis, transference, fundamental psychopathology, regression

Versão inicial recebida em agosto de 2006

Versão revisada recebida em dezembro de 2006 